\title{
Finite element analysis of a composite piston for a diesel aircraft engine
}

The article presents calculations of thermal and mechanical loads of the piston, consisting of two parts: steel and aluminum. The calculations were made using FEM in the Abaqus software. The piston is characterized by a split construction and was equipped with a cooling oil channel. The piston will be used in an aircraft diesel engine characterized by opposite piston movement. The presented geometry of the piston is the next of the ones being developed earlier and contains preliminary assumptions as to the size and main geometrical dimensions. The thermal boundary conditions of the simulation tests assumed defined areas of heat reception surface and heating of the piston by defining a temperature map on its crown. The results of these studies were presented in the form of temperature distribution and heat flux on the surface of the tested element. The strength boundary conditions assumed a mechanical load in the form of pressure resulting from the pressure in the combustion chamber applied to the piston crown surface and the opposite pressure defined on the support at the surface of contact between the piston and the piston pin. The results of these tests were presented in the form of stress distribution on the surface of the tested element. As a result of the analyses carried out, the results constituting the basis for further modernization of the piston geometry were obtained.

Key words: piston, combustion engine, FEM, thermal, mechanical loads

\section{Introduction}

The aviation industry has been recording steady and stable economic growth over the last eight years. Airlines achieve good financial results, generating over 30 billion dollars in profits per year. Operational efficiency has also improved. Flight load ratios in the last year increased to a record $81 \%$ [1]. The aircraft manufacturer, Boeing, assumes a 2.5 -fold increase in the air traffic over the next 20 years. As a result, the industry will require more than 42,000 new aircraft up to 2037. It is anticipated that in 2019 commercial airlines will accept deliveries of over 1,780 new aircraft worth 80 billion USD. About half of the supplies will replace the existing fleet, which significantly contributes to the growth of fuel fleet efficiency [2].

The ultralight aircraft sector is also going in the same direction. Manufacturers of ultralight aircrafts and drones now expect new, light and economical engines with more power. However, the development of a new propulsion system requires numerous research and analyzes. It should be remembered that aircraft propulsion works in the atmosphere, and in very diverse conditions. Variable weather conditions (different pressure, temperature, oxygen level and moisture content) can change in a very short time and affect the engine's operation. The paper presents the problem of thermal load testing of the piston of the PZL-100 engine produced in cooperation with the Lublin University of Technology and WSK "PZL-Kalisz" S.A.

The PZL-100 is a new type of two-stroke internal combustion power unit using an opposing system of pistons placed in a single cylinder to create a combustion chamber. The charge is exchanged via the inlet and outlet ports of the cylinder alternately uncovering and closing the surface of the piston. The dosing of the fual is via a dual common rail system powered by a central high pressure pump. In total, the engine has three cylinders and two crank and piston systems, independently for the inlet and outlet sides, synchronized with each other by means of a belt transmission. figure 1 shows the geometric model of the PZL-100 engine.

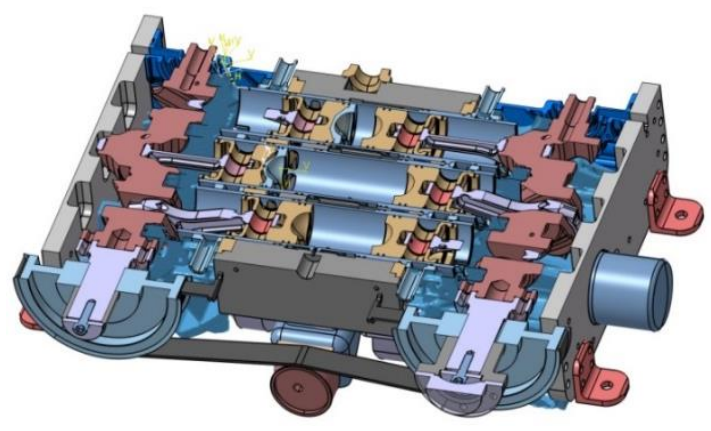

Fig. 1. Geometric model of the PZL-100 engine [3]

The key element of each engine is the piston. The thermal loading of the piston and the resulting temperature profile affect the operation of the drive unit. In diesel engines, the temperature profile in the combustion chamber is largely dependent on the number and orientation of injection holes, injection pressure, injection time, and the geometry of the piston crown $[4,5]$. In the case of exceeded permissible of maximum temperature, loss of fatigue strength of the piston material and plastic changes may occur. The radial deformation of the piston causes changes in nominal dimensions and an increase in friction loss and looseness between the piston and other elements, which may cause plunger or contact with valves $[6,7]$.

Too high temperature in the area of the sealing ring may cause plastic deformation of the piston and increase wear of the sealer or its damage. In addition, overheating of the oil can lead to carbon deposits in the groove of the ring, which can act as a thermal insulator and cause sticking of the ring [8]. The newly developed engine design differs from the classic engine system with the valve system and the fuel injection along the cylinder axis. The combustion chamber in the PZL-100 engine consists of two piston heads. The fuel is injected perpendicularly to the cylinder axis from two injectors installed oppositely. All energy released during combustion process is transferred to the walls of the combustion 
chamber. The numerical analysis of the thermal load on the piston crown and the temperature profile will make it possible to visualize the distribution of temperatures in key areas of the piston, such as the groove of the upper ring and the crown of the bottom. In the classic solution about $3-5 \%$ of fuel energy, in stationary combustion chambers, and 6-8\%, in vortex chambers, is transferred to the piston. If the piston is not cooled, up to $60 \%$ of this heat can pass through the area of the piston ring to the cooling jacket [9]. Additional heat is passed through the bottom to the cooling jacket and from the bottom of the piston through the mist created as a result of the oil splash in the crankcase [10]. The intensity of walking the piston with oil can be increased by a spray jet. The interior of the crankcase is arranged with nozzles through which the oil is continuously sprayed onto the inside of the piston. This technology is the most widespread in gasoline engines and in diesel engines with lower power [11]. Pistons in the most modern racing engines and highperformance diesel engines currently use the design of internal cooling channels and chambers. In this case, the oil is injected through the injector into the central entry channel leading to the chamber located in the piston crown in close proximity to the piston crown. The coolant does not fully fill the chamber, but moves with an oscillating movement up and down with the force corresponding to the displacement of the piston during the reciprocating operation. This leads to a turbulent flow in the liquid cooling channel and intensifies the value of the heat transfer coefficient. The oil flows out of the chamber through channels arranged on the circumference of the piston directly to the crankcase. This type of solution ensures a more efficient flow of thermal energy from the area of exhaust gas interactions and provides a certain thermal insulation for the other elements of the piston. If the piston is cooled with oil, a significant part of this heat is discharged by the oil, reducing the relative amount that passes through the ring region $[12,13]$.

This paper presents the results of simulation tests of thermal and mechanical loads of the PZL-100 self-ignition two-stroke piston. The simulation tests carried out will be used to verify piston design and verify the new piston geometry developed specifically for this engine. The obtained temperature profile will expand the scientific base with new numerical models of heat loads of engine pistons with an opposing piston array with a combustion chamber between two piston heads and a double fuel injection perpendicular to the cylinder axis.

\section{Geometrical model of the piston}

The presented piston consisted of two parts: the upper made of steel $42 \mathrm{CrMn} 04$, the bottom of the aluminum alloy material M174 +. The Figure 2 shows the geometry of the piston.
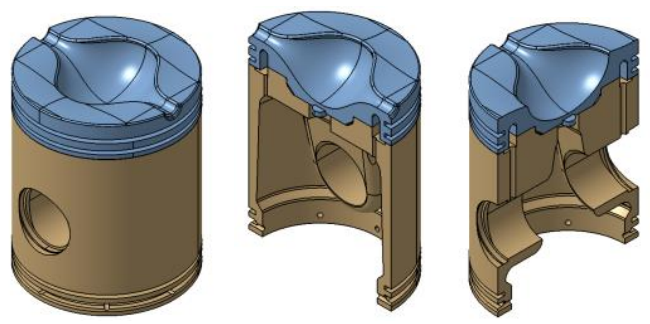

Fig. 2. Geometry of the piston

\section{Boundary conditions}

The research presented in the article was carried out in the Abaqus program using the Finite Element Method. Thermal and strength tests were performed separately, due to the simultaneous separate optimization work devoted to both issues. For both types of tests, the same computational grid was used. Only the properties of the grid were changed in terms of strength and thermal calculations. As demonstrated by preliminary simulation tests, the $1.1 \mathrm{~mm}$ element size is sufficient to obtain reliable calculation results. Increasing the density of the grid beyond this dimension does not significantly affect the calculation, and only causes an increase in their duration. The calculation grid is presented below. Such a geometry contained 394,102 computational elements in the lower part and 140,177 in the upper part. All elements were of the Tet type (Fig. 3).

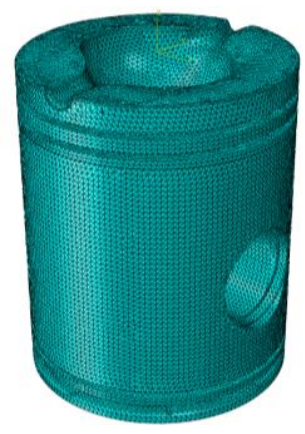

Fig. 3. Calculation grid

The material properties of both parts are presented in the further part of the article. They were divided into strength and thermal properties.

\subsection{Mechanical loads}

Strength tests of the piston consisted in calculating the compressive strength of the piston, which was the result of the applied working pressure from the combustion chamber. The pressure value has been defined on the basis of the previously developed simulation models of engine operation [3].

Below, the boundary conditions that were given to the strength calculations of the piston are shown (Fig. 4). The piston model was constructed in such a way that the applied pressure on the piston's body balanced with the reaction pressure applied on the contact surface of the piston with the piston pin. In order to obtain a balance of forces, pressure was applied to the piston head, up to the contact surface in the first piston ring, the vertical component of the resultant force for this pressure was calculated and converted to the pressure applied to the contact surface of the piston with the piston pin. The pressures on these surfaces have been simulated in the form of a sinusoidal function, reflecting their actual distribution in the case of sliding contact. This mapping of piston working conditions allows a full analysis of the strength in the case of compression.

Defined loads on both sides of the piston allow its stabilization in three-dimensional space during simulation. However, because the calculated grid is not fully symmetrical, this introduces some imbalance of the element being tested. In order to remove unnecessary components of forc- 
es generated from pressures given, it was decided to confirm the piston in an additional place (on the opposite side of the bottom). The place where additional bracing was applied does not affect the results of the simulation.
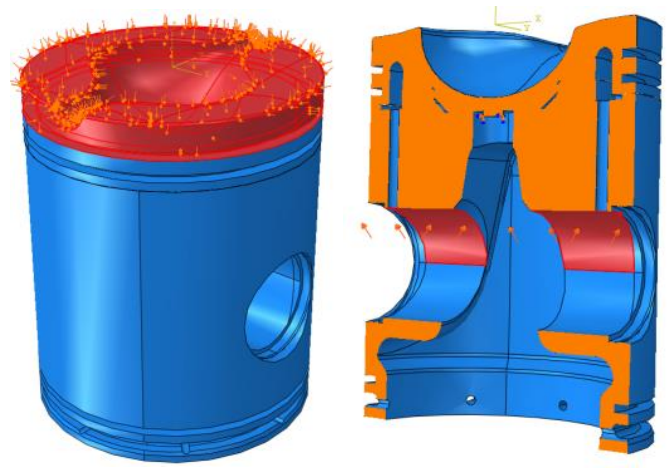

Fig. 4. Surfaces for which the following conditions were given: combustion pressure (left), reaction pressure from the piston pin (right)

The material properties adopted for calculations are presented in the Tables 1 and 2.

Table 1. Material properties accepted for calculation for material M174 +

\begin{tabular}{|l|c|c|}
\hline Parameter & Unit & Value \\
\hline Poisson`s Ratio & - & 0.33 \\
\hline Density & $\mathrm{kg} / \mathrm{m}^{3}$ & 2750 \\
\hline Young`s Modulus & $\mathrm{GPa}$ & 85 \\
\hline
\end{tabular}

Table 2. Material properties accepted for calculation for material $42 \mathrm{CrMn04+}$

\begin{tabular}{|l|c|c|}
\hline Parameter & Unit & Value \\
\hline Poisson`s Ratio & - & 0.3 \\
\hline Density & $\mathrm{kg} / \mathrm{m}^{3}$ & 7700 \\
\hline Young`s Modulus & $\mathrm{GPa}$ & 210 \\
\hline
\end{tabular}

\subsection{Thermal loads}

Because the piston consists of two independent parts, it was necessary to give a coefficient of thermal conductivity occurring on the contact surface of two different materials (Fig. 5). The properties of this contact are shown in the Table 3, and the common (contact) surfaces have been connected via the Tie function [3].

Table 3. Heat flow conditions between surfaces [3]

\begin{tabular}{|c|c|}
\hline $\begin{array}{c}\text { Thermal conductivity coefficient } \lambda \\
{[\mathrm{W} / \mathrm{m} \mathrm{K}]}\end{array}$ & $\begin{array}{c}\text { Value of the gap between } \\
\text { surfaces }[\mathrm{m}]\end{array}$ \\
\hline 700 & 0 \\
\hline 0 & 0.001 \\
\hline
\end{tabular}

Table 4 and 5 shows additional material data for thermal calculations for both materials used.

Table 4. Material properties of aluminium alloy called M174 + [1]

\begin{tabular}{|c|c|}
\hline Temperature $[\mathrm{K}]$ & Heat transfer coefficient $\left[\mathrm{W} / \mathrm{m}^{2} \mathrm{~K}\right]$ \\
\hline 293 & 130 \\
\hline 623 & 140 \\
\hline
\end{tabular}

Table 5. Material properties of steel called 42CrMn04 [1]

\begin{tabular}{|c|c|}
\hline Temperature $[\mathrm{K}]$ & Heat transfer coefficient $\left[\mathrm{W} / \mathrm{m}^{2} \mathrm{~K}\right]$ \\
\hline 293 & 33.5 \\
\hline 523 & 34.0 \\
\hline 773 & 34.2 \\
\hline
\end{tabular}

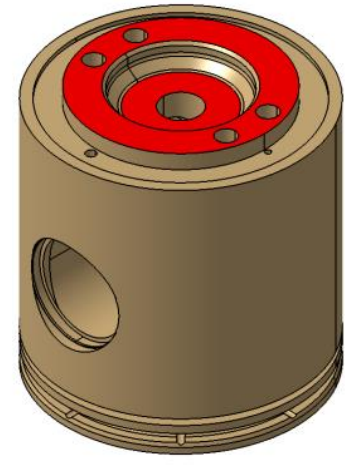

Fig. 5. Contact surface of two different materials

As boundary conditions, heat transfer coefficient map on the piston crown taken from CFD combustion model and constant piston crown temperature $850 \mathrm{~K}$ were assumed [3].

However, the following (Figs 6-9) shows the method of cooling the piston, which will probably be used in the actual version of the engine. Oil washing takes place via the cooling channel, but does not occur from the inside of the piston. Figures below shows the inner surface of the piston and the oil channel for which the boundary condition of the oil contact with the surfaces shown is given.

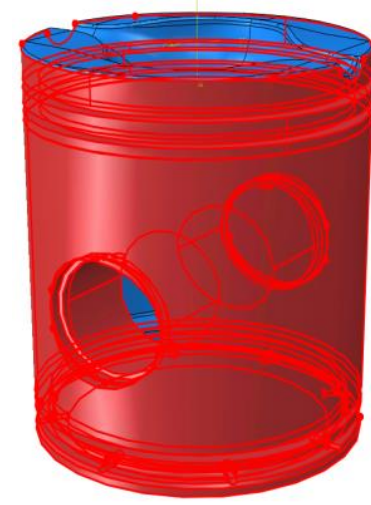

Fig. 6. The boundary condition of the piston's thermal load - side surfaces - temperature: $393 \mathrm{~K}$, heat transfer coefficient: 500 $\mathrm{W} /\left(\mathrm{m}^{2} \mathrm{~K}\right)$

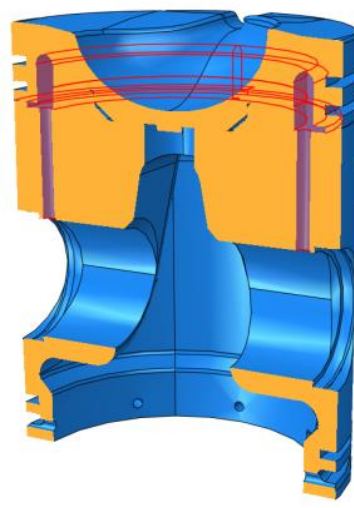

Fig. 8. Additional boundary condition of the piston's thermal load - oil channel - temperature: $373 \mathrm{~K}$, heat transfer coefficient: $2500 \mathrm{~W} /\left(\mathrm{m}^{2} \mathrm{~K}\right)$

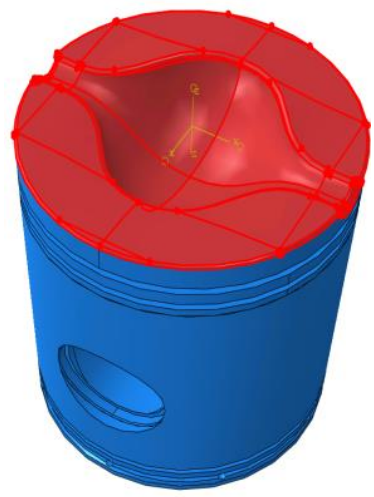

Fig. 7. The boundary condition of the piston thermal load - bottom - temperature: $850 \mathrm{~K}$, heat transfer coefficient: map

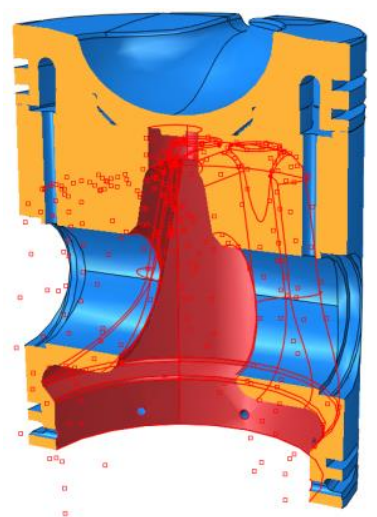

Fig. 9. Additional boundary condition for the thermal load of the piston - internal surfaces - temperature: $393 \mathrm{~K}$, heat transfer coefficient: $500 \mathrm{~W} /\left(\mathrm{m}^{2} \mathrm{~K}\right)$ 


\section{Results}

\subsection{Results of mechanical loads}

Figure 10 presents the distribution of stresses on the surface and in the longitudinal sections of the piston. The distributions are marked with characteristic digits of the place. In order to improve the readability of the results, the scale was limited to $120 \mathrm{MPa}$. The maximum stress value is $250 \mathrm{MPa}$. The values in the range of 120-250 MPa are marked in gray. They are located inside the oil channel in the piston crown (1) and on the surface cooperating with the piston pin (2). The high value of stresses in the oil duct results from the fact that the outer part of the steel piston crown is not in contact with the aluminum bottom part of the piston. Between these parts there is a gap through which oil flows out. As a result, the outside of the bottom is bent. The high value of stresses in the second place results from
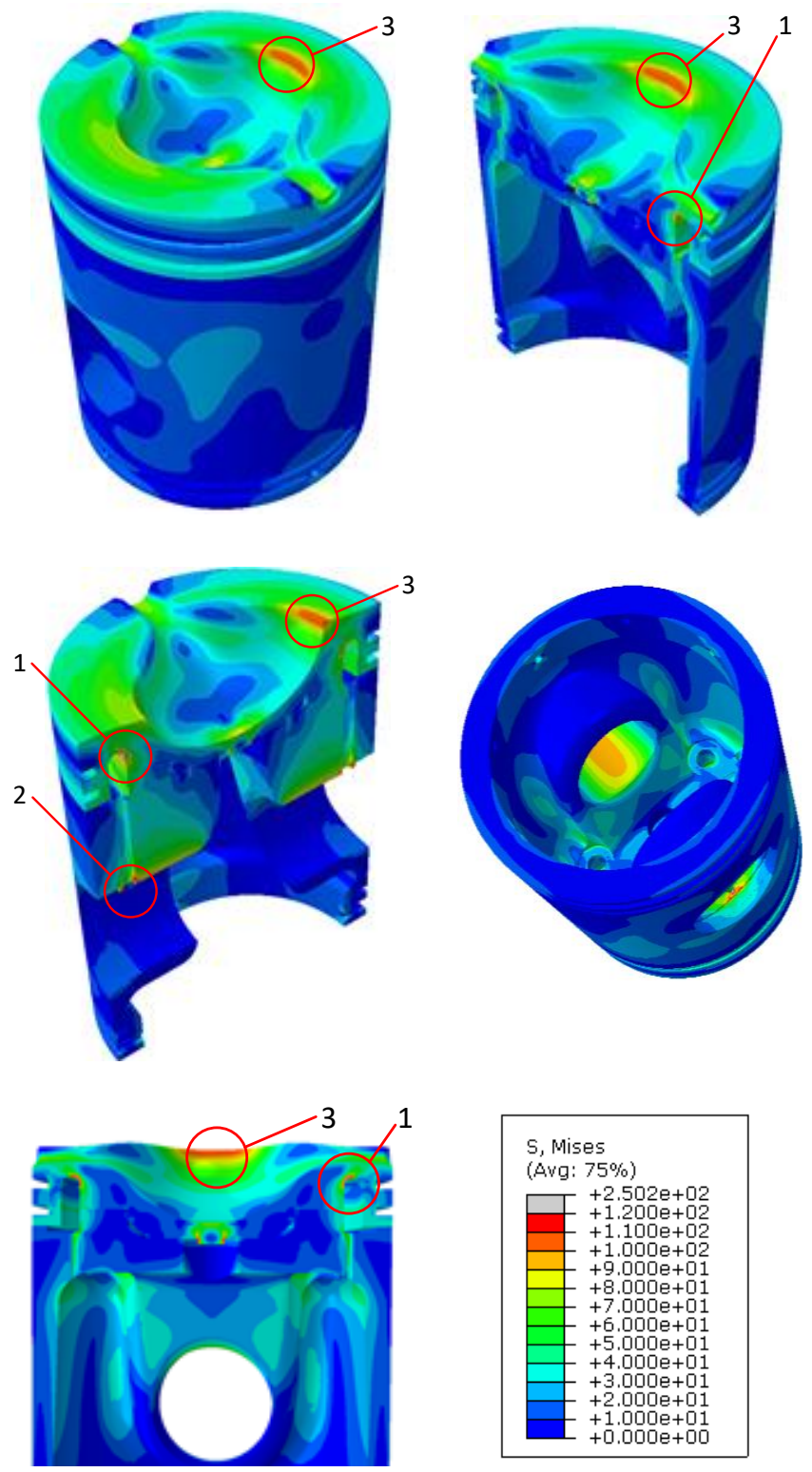

Fig. 10. Distribution of stresses on the surface of the piston the pressure of the piston pin. Significant stress values were also observed at the edge of the combustion chamber (3). This is due to the bending of the piston crown, which is supported underneath by a piston pin.

\subsection{Results of thermal loads}

Figure 11 shows the temperature distribution on the surface and in the longitudinal sections of the piston. The maximum temperature was observed at the edge of the combustion chamber (T1) and it is $758 \mathrm{~K}$. This location results from a small radius of edge rounding, from which the heat flow is hindered.

For the bottom part of the piston, made of aluminum alloy, the temperature reaches the value of $523 \mathrm{~K}$ (T2). The location of maximum temperature is located on the border of the piston division.
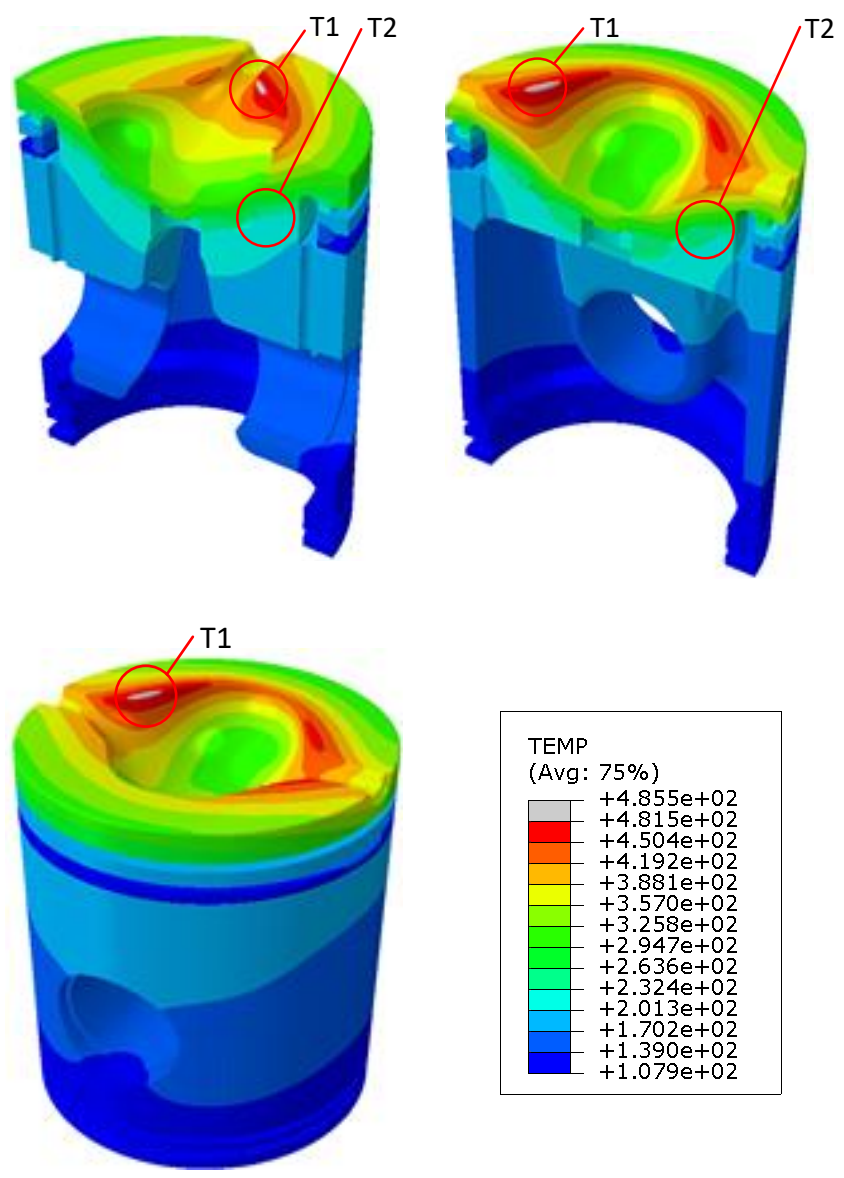

Fig. 11. Temperature distribution on the surface of the piston

Figure 12 shows the distribution of the density of the HFL heat flux flow on the surface and in the longitudinal sections of the piston. The maximum values were observed at the interface between the piston elements (H1). This is due to the accumulation of the heat flux that flows through the constrictions of the material with a small cross-section. Other characteristic places of occurrence of increased heat flow are recesses around the stream of injected fuel (H2) and inside the combustion chamber $(\mathrm{H} 3)$. The reason for this location is the combination of a high temperature value and a small thickness of the piston crown. 

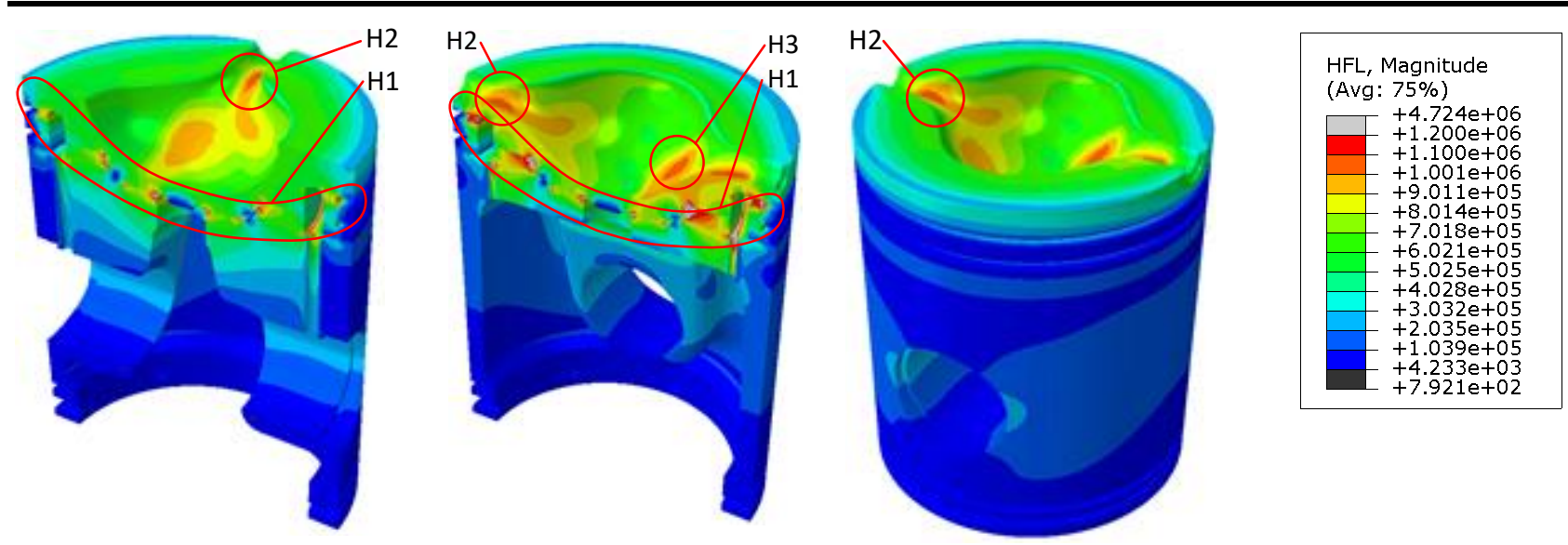

Fig. 12. Distribution of heat flow density on the surfaces of the piston

\section{Summary}

As a result of the analysis of the stress distribution, temperature and heat flux, it can be stated that the maximum values do not exceed the limit values for the materials used. The plunger in the pre-configured form will be made and used in the engine being constructed.

\section{Acknowledgements}

Acknowledgement: This work has been realized in the cooperation with The Construction Office of WSK "PZL-KALISZ" S.A." and is part of Grant Agreement No. POIR.01.02.00-00-0002/15 financed by the Polish Nation-al Centre for Research and Development.

\section{Nomenclature}

FEM finite element method

USD United States dollar
CFD computational fluid dynamics

Tet tetrahedronal

\section{Bibliography}

[1] Boeing Commercial Market Outlook Rapport 2018.

[2] IATA Economic performance of the airline industry 2018

[3] MAGRYTA, P., GECA, M. FEM analysis of piston for aircraft two stroke diesel engine. MATEC Web of Conferences. 2019, 252, 07004. DOI: 10.1051/matecconf/ 201925207004

[4] KÜNZEL, R., WERKMANN, M., TUNSCH, M. Piston related noise with diesel engines - parameters of influence and optimization. SAE Technical Paper 2001-01-3335. 2001.

[5] ABID, M., BANNIKOV, M., CHATTHA, J.A., 3-D finite element analysis of a diesel engine piston. 2005.

[6] MAHLE GmbH (Ed.). Pistons and engine testing. 1st Edition. 2012.

[7] NASIF, G., BARRON, R., BALACHANDAR, R. Numerical simulation of piston cooling with oil jet impingement. Journal of Heat Transfer. 2016, 138(12).

Konrad Pietrykowski, PHd, Eng. - Faculty of Mechanical Engineering at the Lublin University of Technology.

e-mail: k.pietrykowski@pollub.pl

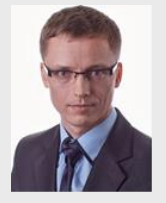

[8] NASIF, G., BARRON, R. M., BALACHANDAR, R. Heat transfer due to an impinging jet in a confined space. ASME J. Heat Transfer. 2014, 136.

[9] CHALLEN, B., BARANESCU, R. Diesel engine reference book. 2nd edition. SAE Warrendale 1999.

[10] AGARWAL, A.K., GOYAL, S.K., SRIVASTAVA, D.K., Time resolved numerical modeling of oil jet cooling of a medium duty diesel engine piston. Int. Commun. Heat Mass Transfer. 2011, 38(8), 1080-1085.

[11] CHALLEN, B., BARANESCU, R. Diesel engine reference book. Second Edition. Butterworth-Heinemann 1999.

[12] ALCOCK, J.F. Heat transfer in diesel engines. International HeatTransfer Conference, Boulder, Colorado. 1961, 174.

[13] OWEN, N.J., ROBINSON, K., JACKSON, N.S. Quality assurance for combustion chamber thermal boundary conditions - a combined experimental and analytical approach. SAE Technical Paper 931139. 1993.

\footnotetext{
Paweł Magryta, MEng. - Faculty of Mechanica Engineering at the Lublin University of Technology. e-mail: p.magryta@pollub.pl
}

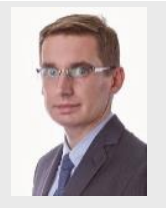

Krzysztof Skiba, MEng. - Faculty of Mechanical Engineering at the Lublin University of Technology. e-mail: k.skiba@pollub.pl 